\title{
CLUSTERIZATION AND ANOMALIES OF FLUCTUATIONS IN WATER-ALCOHOL SOLUTIONS OF LOW CONCENTRATIONS
}

\author{
V. Eu. Chechko, T. V. Lokotosh, N. P. Malomuzh, V. G. Zaremba, V. Ya. Gotsul'sky \\ Odessa National University, \\ 2 Dvorjanska Str., Odessa, 65100, Ukraine
}

(Received July 2, 2002; received in final form December 28, 2002)

\begin{abstract}
A new approach for the explanation of the anomalous increase of the concentration fluctuations in dilute water-alcohol solutions is developed. This phenomenon is assumed to be connected with the peculiarities of clusrerization effects in a system approaching the pseudospinodal - the instability line for a system containing only the elementary clusters. It was proposed that the pseudospinodal separates the states of solution with different cluster structure. The pseudospinodal position is estimated. The behaviour of integral intensity of the molecular light scattering is described. To specify the fine details, experimental investigation of the molecular light scattering in water-glycerol solution was performed. The peculiarities of equilibrium and metastable crystallizations in this solution are considered.
\end{abstract}

Key words: hydrogen bond, clusterization, anomalous fluctuations, pseudospinodal.

PACS number(s): 61.20.Og, 61.60.+m

\section{INTRODUCTION}

There exists the vast literature on molecular light scattering in water-alcohol solutions (see $[1,2]$ ). It was shown that at molar concentrations $x_{n} \sim(0.2 \div 0.5)$ the maximum of the integral intensity $I_{\mathbf{q}}$ is observed (the 'normal' peak). In particular, for water-tert-butyl solution the integral intensity $I_{\mathbf{q}}$ at $x=0.15$ increases by about five times. Such a behaviour of $I_{\mathbf{q}}$ demonstrates the tendency to demixing. In the most evident form this tendency is characteristic for a water- $\beta$-picoline solution and those similar to it. In some temperature interval these solutions demixe. To such cases the closed-loop diagrams with the upper and lower critical points correspond [3,4].

In this situation it was very surprising to observe in water-alcohol solutions the additional narrow peak of the integral intensity at $x_{a} \sim 0.05$ (see references in [1,5-7]). So, for above mentioned water-tert-butyl solution the very clear maximum is observed near $x_{a} \sim 0.03$, where $I_{\mathbf{q}}$ increases approximately by a factor of 10 and becomes higher than the maximum of integral intensity observed at $x_{a} \sim 0.15$. Besides, the half-width of the additional peak is essentially less in comparison with that of "normal' peak. Here it is worthy to note two characteristic features of additional peak for different diluted wateralcohol solutions: 1$)$ it is observed at close concentrations $(x=(0.03 \div 0.06))$, though the sizes and configurations of admixture molecules are essentially different; 2) its height increases monotonously when temperature decreases. These facts testify about different nature of the additional and 'normal' peaks. This conclusion is also supported by different dependencies of peaks parameters on the ratio of normal and heavy components of water [1]. It means that the thermodynamic notions used for the explanation of nature of the 'normal' peak are not appropriate to interpret the appearance of the additional one.
A more careful analysis of the additional maximum of the integral intensity showed that the observed picture is very sensitive to the method used for the preparation of solution. So, in [6] the anomalous increase of $I_{\mathbf{q}}$ was observed only after vacuum distillation of the solution. A similar anomaly in it was observed in [1] after preliminary heating on $(50 \div 70)^{\circ} \mathrm{C}$. In $[8]$ the additional sharp peak of the integral intensity was observed, when a water-glycol solution was held at the experimental temperature during $(1 \div 2)$ days. These facts can testify to a considerable role of impurities or very slow relaxation processes in solutions, though the details of such an influence are still unclear.

In $[8]$ the data on the integral intensity in water-glycol solution was completed by the experimental study of the time correlation function for the integral intensity $K_{\mathbf{q}}=\left\langle I_{-\mathbf{q}}(t) I_{\mathbf{q}}(0)\right\rangle$, where $\mathbf{q}$ is the scattering wave vector. Assuming the applicability of the Ziegert's relation:

$$
K_{\mathrm{q}}(t)=\left\langle I_{\mathrm{q}}^{2}(0)\right\rangle\left(1+\left|g_{\mathrm{q}}(t)\right|^{2}\right)
$$

between $K_{\mathbf{q}}(t)$ and the autocorrelation function $g_{\mathbf{q}}(t)=$ $\left\langle\mathbf{E}_{-\mathbf{q}}(t) \mathbf{E}_{\mathbf{q}}(0)\right\rangle$ of the electric field strength $\mathbf{E}_{\mathbf{q}}(t)$ and approximating $g_{\mathbf{q}}(t)$ with the help of an exponent:

$$
g_{\mathbf{q}}(t)=g_{\mathbf{q}}(0) \exp \left(-t / \tau_{q}\right)
$$

the authors [8] have studied the concentration dependence of the relaxation time $\tau_{q}$. It had been shown that at approaching $x=0.044 \tau_{q}$ increases by a factor of $10^{2}$.

The additional information on the properties of fluctuations in the low concentrations region is given by experimental measurements of the heat capacity $C_{p}$ and compressibility $\beta_{T}$, carried out in [9-11]. It was shown 
that near $x_{a} C_{p}$ can be represented as a sum of the regular contribution and the relatively small peak.

Thus, summarizing the results obtained in the cited works we should conclude that the increase of the integral intensity of molecular light scattering by a factor of 10 as well as the respective slowing down the relaxation processes testify about (1) noticeable deviations of dilute water-alcohol solutions from ideality and (2) the similarity with the behaviour of a system near the critical point or spinodal. Besides, the close values of concentrations $(x \sim 0.05)$ for the additional peak for different wateralcohol solutions point out on the collective nature of the phenomenon. More definitely, anomalous properties of these solutions are caused by association (clusterization) processes in them.

To explain these regularities the following approaches were developed $[11,12]$. Taking into account the growth of fluctuations, the authors of [12] assumed that the low concentration water-alcohol solution is close to so called unattainable critical point (UCP). Within this picture the behaviour of fluctuations seems to be explained. However, it is very difficult to motivate so small magnitudes of concentration in UCP. Besides, the close values of $x_{a}$ for water-alcohol solutions with different sizes and configurations of admixture molecules remain to be unsolved puzzle. It is also impossible to understand why UCP is situated near the equilibrium crystallization curve and the integral intensity grows when temperature decreases. Hence, this explanation raises strong objections.

Another interpretation of the anomalous growth of fluctuations in dilute water-alcohol solutions was given in [11]. There the main attention was paid to the close magnitudes of $x_{a}$ for different solutions. According to [11], this fact is connected with the characteristic manifestation of water structure. More exactly, at $x \approx 0.05$ the water crystal-like structure is expected to be destroyed [13]. In other words, the smeared structural phase transition takes place. Such an assumption is connected with the existence of non-scalar order parameter. Therefore, within this approach it is very difficult to explain the anomalous growth of the integral intensity of polarized light scattering. Besides, one can speak about the structural phase transition only if the fraction volume of regions with crystal-like ordering is large enough $\varphi \geq 0.5$. However, the estimates made in [14] show that even near the melting point $\varphi$ does not exceed 0.1 and rapidly diminishes with temperature. Other attempts to explain the nature of anomalous growth of fluctuations in dilute water-alcohol solutions are not known to us.

In the present paper we develop a new approach to the problems being discussed. To specify some fine details, the measurements of the integral intensity of molecular light scattering for dilute water-glycerol solutions were carried out. The boundary of supercooled states in them was studied. The cluster model for the structure of water-alcohol solutions is proposed. Considering clusters as independent elements of substructure, we discuss the question about the instability of these solutions. The instability of homogeneous solution is identified with that having place at approaching the spinodal. Another factor taken into account is the destruction of elementary clusters at reaching the percolation threshold. The combination of these factors can lead to smeared phase transition of demixing type. We tried to explain: 1) the anomalous growth of concentration fluctuations and slowing down the relaxation processes; 2) the small values of characteristic concentrations; 3 ) the temperature dependence of the peak position of integral intensity; 4) the anomalous lowering of the boundary of supercooled states near the characteristic concentration $\left.x_{a} ; 5\right)$ the peculiarities of heat capacity. The paper is organized as follows: in the first two Sections we present the results of experimental investigation of water-glycerol solution and in the next five Sections we formulate the main positions of our approach and discuss the possible consequences.

\section{INTEGRAL INTENSITY OF MOLECULAR LIGHT SCATTERING IN WATER-GLYCEROL SOLUTIONS}

To reduce the influence of the impurities, in particular, of the gas bubbles, the solution was held at fixed conditions during $1 \div 2$ days. Directly at the exposition temperature the solution was held during not less than 1.5 hours. The measurements of the integral intensity were carried out at the scattering angle $\theta=90^{\circ}$, the incident beam wave length was $\lambda=632 \mathrm{~nm}$. Temperature was controlled within $0.1 \mathrm{~K}$.

The experimental results are presented in Fig. 1-3. As we see, the anomalous increase of the integral intensity takes place in the interval of molar concentrations $0.04<x<0.06$. The integral intensity increases monotonously when temperature decreases. Note, these experiments were performed at temperatures $t^{\circ} \geq 3^{\circ} \mathrm{C}$.

A further lowering of temperature for large enough cuvettes is limited by the equilibrium crystallization curve $T_{\text {cr }}(x)$ (see Fig. 4$)$. The temperature $T_{\max }$, at which the integral intensity reaches its maximum, increases systematically with molar concentration (see Fig. 2 and 3 ). The maximum value of the integral intensity was observed at the concentration $x_{a}=0.046$ and the temperature $t^{\circ}=3^{\circ} \mathrm{C}$. The last is distant from the equilibrium crystallization point of water-glycerol solution on $8^{\circ} \mathrm{C}\left(T_{\mathrm{cr}}(0.046)=-5^{\circ} \mathrm{C}\right)$. Near the crystallization point the formation of numerous nuclei should take place. To eliminate their influence on molecular light scattering the measurements of the integral intensities at lower temperatures were not performed.

The concentration dependence of $T_{\max }$ is not compatible with the representations developed in $[11,12]$. Indeed, if the parameters of solution are close to those for UCP, the intensity maximum should be observed at the fixed temperature. On the other hand, if the growth of fluctuations is connected with the destruction of the water crystal-like structure [12], the characteristic concentration should diminish with temperature. So, the expected and observed tendencies are opposite. 


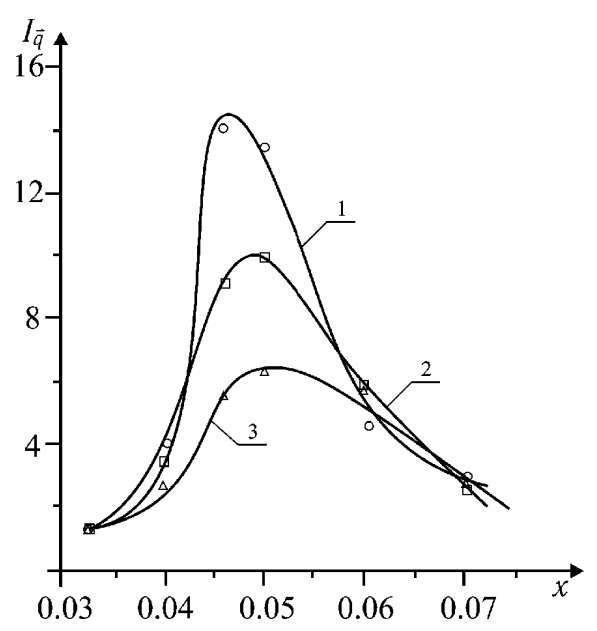

Fig. 1. Concentration dependence of the integral intensity $I_{\mathbf{q}}$ (arbitrary units) for water-glycerol solution at different temperatures: $\triangle-10^{\circ} \mathrm{C} ; \bigcirc-3^{\circ} \mathrm{C} ; \square-5^{\circ} \mathrm{C}$.

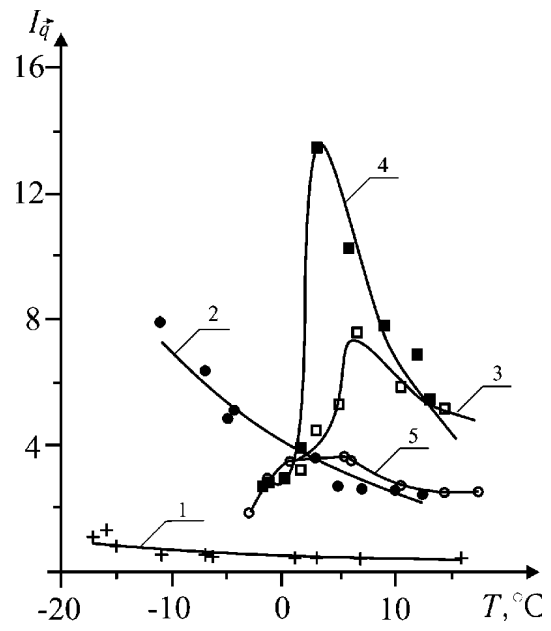

Fig. 2. Temperature dependence of the integral intensity $I_{\mathbf{q}}$ (arbitrary units) at different concentrations: $+-0.032 ; \bigcirc-0.037 ; \square-0.040 ; \mathbf{\square}-0.050 ; \bullet-0.070$.

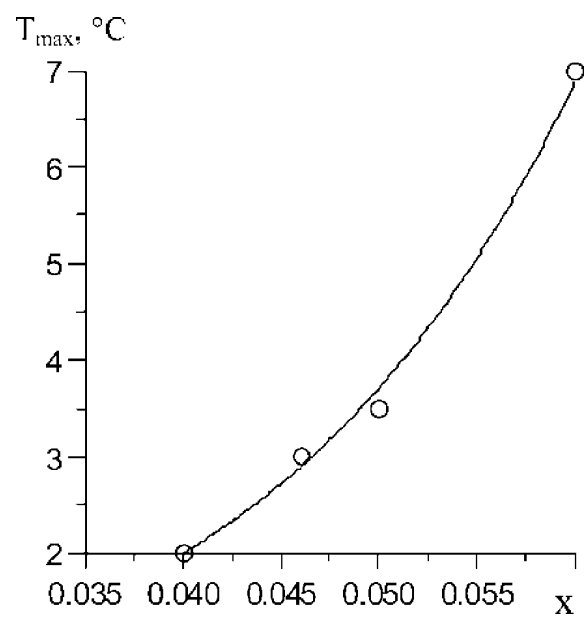

Fig. 3. Concentration dependence of $T_{\max }$ for water-glycerol solution.

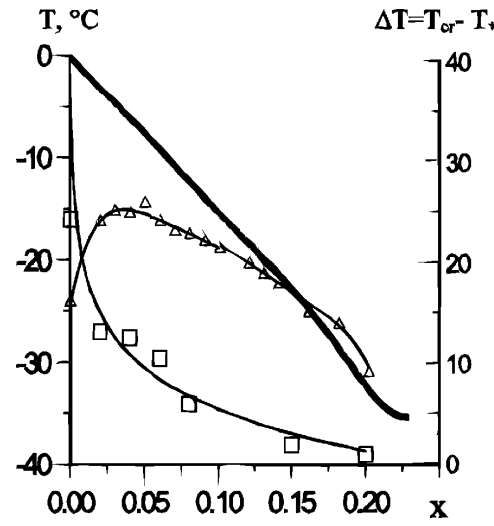

Fig. 4. Concentration dependence of the equilibrium crystallization temperature $T_{\mathrm{cr}}$ (solid line) of water-glycerol solution, taken from [15], the boundary of supercooled states ( $\square$ ) and their difference $\Delta T=T_{\mathrm{cr}}-T_{*}(\Delta)$.

\section{ANALYSIS OF CRYSLALLIZATION PROCESS IN THE NARROW CAPILLARIES}

To complete the information about the properties of fluctuations obtained with the help of molecular light scattering, we studied the crystallization of dilute wateralcohol solutions placed in narrow capillaries. The crystallization is characterized by the inverse time needed for the formation of the first critical nucleus whereupon the crystallization of a system occurs practically in a moment.

The filtered solution was pulled in the fresh-extended glass capillaries with the inside diameter $D=0.03 \mathrm{~cm}$. After that the both ends of capillaries were welded. Each capillary contains about $0.02 \mathrm{~cm}^{3}$ of a solution and for each concentration 200 samples were prepared. Then the capillaries were placed in liquid playing the role of thermostat. The samples were held at the exposition temperature during one hour. After this the number of samples with crystallized solution was determined with the help of polarized light. Further the temperature of a thermostat had been lowered on $0.1^{\circ} \mathrm{C}$ and the described procedure was repeated several times up to the full crystallization of all samples.

A small number of samples which crystallized on the first step probably due to the impurities, was excluded from consideration. The respective histogram was built. At the definite temperature $T_{*}(x)$ this histogram has a sharp enough maximum. Namely, $T_{*}(x)$ was taken for the boundary of metastable states of solution at a given concentration. The concentration dependence of $T_{*}$ as well as the equilibrium crystallization temperature $T_{\mathrm{cr}}(x)$ is presented in Fig. 4 . The difference $\Delta T(x)=T_{*}-T_{\text {cr }}$ can be considered as the measure of allowable supercooling. We see that $\Delta T$ and the integral intensity of scattered light reach their maximum values at the same concentration $x_{a}$. So, we have to conclude that the increase of fluctuations in water-alcohol solution at approaching the pseudospinodal suppresses the nucleation process. 


\section{THE MAIN ASSUMPTIONS}

The main feature of water-alcohol solutions is the ability of molecules of both components to form strong Hbonds. If the H-bond binding energies for different pairs satisfy the inequality $[16,17]$ :

$$
J_{\text {ww }}, I_{\text {aa }} \leq(\ll) J_{\text {wa }}
$$

where ' $w$ ' and ' $a$ ' denote the type of molecule (w - water, a - alcohol), the strongly bonded water-alcohol associates (clusters) form. A water-glycerol solution is typical example of such a behaviour. If the concentration of admixture molecules is small, the elementary cluster includes only one or two alcohol molecules and $6 \div 10$ water molecules. The characteristic size of an elementary cluster is about $(5 \div 7) A$. The configuration of $\mathrm{H}$-bonds inside elementary cluster differs from that in bulk water. The life-time of such clusters is substantially greater than the characteristic time of binary collisions as well as the life-time for clusters, existing in pure water above the melting temperature [14]. So, the elementary cluster can be treated as a pseudoparticle. These statements can be confirmed by the reasons from [18], in which the structure of water-electrolyte solutions was studied with the help of computer simulations. It had been shown that the strong Coulombic field of an ion changes the water structure only inside $(1 \div 2)$ coordination shells.

The simple cluster picture of water-alcohol solution will remain correct, until the volume fraction of elementary clusters does not exceed the value corresponding to the percolation threshold $\varphi_{\mathrm{p}}$ for spherical particles [19]:

$$
\varphi \leq \varphi_{\mathrm{p}} \approx 0.2
$$

In this case the behaviour of the solution is similar to that for low concentration water-micellar solution. At some concentration the last can demixe (see [20]). However, the demixing in water-alcohol solution does not occur since the increase of pseudoparticles concentration leads to the destruction of elementary clusters and the appearance of mesostructures of another types.

Thus, we expect that the behaviour of dilute wateralcohol solution is determined by the relative disposition of the threshold concentration $x_{\mathrm{p}}\left(x_{\mathrm{p}}=\varphi_{\mathrm{p}} /\left(v_{\mathrm{cl}} n\right)\right)$, where $v_{c l}$ is the volume of on elementary cluster and $n$ is the number water density) and the spinodal $(S)$ of waterpseudoparticles solution, so called pseudospinodal. The possible types of phase diagrams in the region of low concentrations are presented in Fig. 5 .

The phase diagrams of a-type correspond to solutions with the upper pseudocritical point, and of b-type to those with the lower one. The type of phase diagram is defined by the character of pseudoparticles interaction in water.

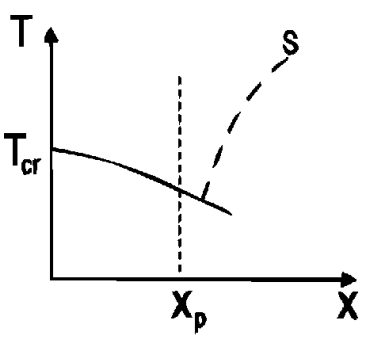

a)

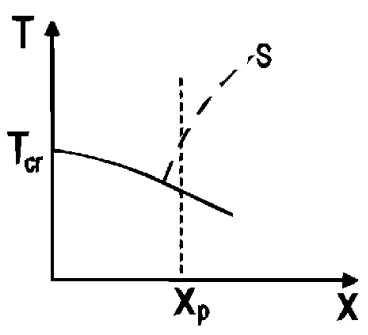

a)

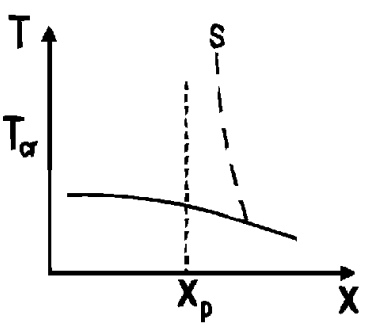

b)

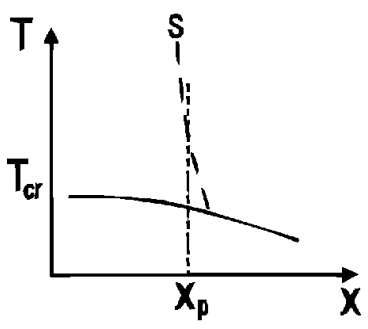

b')
Fig. 5. Possible relative dispositions of the equilibrium crystallization line $(-)$, the stability boundary $(--)$ and the percolation threshold ( $\left.\begin{array}{l}1 \\ 1\end{array}\right)$ for water-alcohol solutions.

At approaching the pseudospinodal the fluctuations of pseudoparticles density should noticeably increase. However, on the pseudospinodal they remain limited. The remoteness from the threshold concentration $x_{\mathrm{p}}$ influences also the intensity of fluctuations. From this point of view in the water-alcohol solution of a-type the strongest fluctuations should take place near the intersection point of $S$ with the equilibrium crystallization line. In fact, a water-glycerol solution demonstrates namely this type of behaviour.

\section{ESTIMATE OF $x_{\mathrm{p}}$}

Let $v_{\mathrm{cl}}$ be the volume of an elementary cluster. The percolation threshold takes place [19] at

$$
\varphi_{\mathrm{p}}=n_{\mathrm{p}} v_{\mathrm{cl}} \approx 0.2
$$

where $n_{\mathrm{p}}$ is the numerical density of the alcohol molecules. From here it follows that the characteristic concentration $x_{\mathrm{p}}$ equals

$$
x_{\mathrm{p}}=\frac{n_{\mathrm{p}}}{n_{\mathrm{w}}} \approx 0.2 \frac{v_{\mathrm{w}}}{v_{\mathrm{cl}}}
$$

where $v_{\mathrm{w}}$ is the volume per water molecule. Besides, writing (3) we supposed that the elementary cluster includes only one molecule of alcohol. In accordance with our 
main assumptions the ratio $v_{\mathrm{w}} / v_{\mathrm{cl}}$ is about 0.1 . Therefore, $x_{\mathrm{p}}$ should be approximately equal to $(0.02 \div 0.04)$. This estimate is rather less than the characteristic concentration $x_{\mathrm{ch}}$, at which the integral intensity reaches its maximum for the most of water-alcohol solutions. There are two simple possibilities to improve the theoretical estimate of $x_{\mathrm{p}}$. One of them is connected with some diminution of the elementary cluster size. Another one seems to be more realistic: an elementary cluster includes two alcohol molecules. Indeed, assuming that an elementary cluster in water-glycerol solution includes two glycerol molecules, we get the estimate

$$
x_{\mathrm{p}} \approx(0.04 \div 0.08) \text {, }
$$

which is consistent with values of $x_{\mathrm{ch}}$, observed in experiments. This possibility can be grounded by the following arguments. Each glycerol molecule forms $4 \div 6 \mathrm{H}$-bonds with the nearest water molecules. Two glycerol molecules can form up to $(10 \div 12) \mathrm{H}$-bonds. Among possible Hbond configurations created by them the most stable and energetically profitable are the rings. So, in hexagonal ice and pure water the rings, including $6 \mathrm{H}$-bonds, are the main elements of their structures [21]. From this point of view it is clear that the simplest stable cluster, including not less than two H-bond rings, should be formed by two glycerol molecules. The role of 6 -H-bond rings in the clusterization of pure water, in its normal and supercooled states, is discussed in detail in [14].

Until $x<x_{\mathrm{p}}$ the contribution of relatively weak intercluster interaction to the osmotic pressure can be evaluated with the help of the van der Waals equation:

$$
P_{\mathrm{osm}}=\frac{k_{\mathrm{B}} T}{v-v_{0}}-\frac{a}{v^{2}},
$$

where $v$ is the volume per one cluster, $v_{0}=4 v_{\mathrm{cl}}$ and $k_{\mathrm{B}}$ is the Boltzmann constant. The pseudocritical temperature $T_{c}$ and the volume $v_{c}$ take the values [23]:

$$
\begin{aligned}
& T_{c}=\frac{8 a}{27 v_{0}}, \\
& v_{c}=3 v_{0} \approx 12 v_{\mathrm{cl}} .
\end{aligned}
$$

In accordance with $(7)$ the concentration of alcohol molecules $x_{c}=2 v_{\mathrm{w}} / v_{c} \approx(0.017 \div 0.034)$ at the pseudocritical point is close to $x_{p}$, that testifies about the self-consistency of our approach.

In the opposite case, $x>x_{\mathrm{p}}$, the intercluster interaction becomes considerable. The elementary clusters destroy and more complex clusters (or homogeneous media without clear nanostructure) form. Equation (6) should be modernized. Hence the respective "phase transition" should be smeared. More exactly, at crossing the pseudospinodal a system remains stable though fluctuations in it can grow considerably.

\section{FLUCTUATIONS OF CONCENTRATION NEAR THE PSEUDOSPINODAL}

To describe qualitatively the anomalous growth of fluctuations at approaching the pseudospinodal it is natural to apply the Landau-Ginsburg formalism with the Hamiltonian [22-24]:

$$
\begin{aligned}
H & =\int d V\left[\frac{1}{2} a_{2} \psi^{2}+\frac{1}{2} b_{2}(\nabla \psi)^{2}\right. \\
& \left.+\frac{1}{3} a_{3} \psi^{3}+\frac{1}{4} a_{4} \psi^{4}+\ldots\right],
\end{aligned}
$$

where the order parameter $\psi$ is defined as a difference between the number density $n_{c l}$ of the elementary clusters and its value on the pseudospinodal:

$$
\psi=n_{\mathrm{cl}}-n_{\mathrm{cl}}\left(x_{s}(T)\right) .
$$

The coefficients $a_{k}$ have the structure (see [23]):

$$
\begin{aligned}
& a_{2}=a_{2}^{(0)}+2 a_{3}^{(0)} \psi_{0}+3 a_{4}^{(0)} \psi_{0}^{2} \\
& a_{3}=a_{3}^{(0)}+\frac{9}{2} a_{4}^{(0)} \psi_{0},
\end{aligned}
$$

where $\psi_{0}$ is the equilibrium order parameter on the pseudospinodal. The initial values of coefficients can be identified with the isothermal derivatives of pressure of the elementary clusters gas:

$$
a_{k}^{(0)}=\left.\frac{\partial^{k} P_{\mathrm{osm}}}{\partial n_{\mathrm{cl}}^{k}}\right|_{T}, \quad k=2,3,4 .
$$

Near the pseudospinodal with satisfactory accuracy:

$$
a_{2}=L_{0}+L_{2}\left(T-T_{s}(x)\right)^{2}+\ldots
$$

or

$$
a_{2}=L_{0}+\tilde{L}_{2}\left(x-x_{s}(T)\right)^{2}+\ldots
$$

where $L_{0}=L_{0}(x) \neq 0$ because the pseudospinodal corresponds to the smeared phase transition and $\tilde{L}_{2}=L_{2} \times$ $\left[\frac{d T_{\mathrm{s}}(x)}{d x}\right]^{2}$. These expansions for $a_{2}$ have sense only near pseudospinodal points $\left(x_{\mathrm{s}}, T_{\mathrm{s}}\right)$ for which $x_{\mathrm{s}}(T) \approx x_{\mathrm{p}}$. For $x_{\mathrm{p}}<(\ll) x_{\mathrm{s}}$ the coefficient $a_{2}$ has no peculiarities. The coefficient $a_{3}$ should be different from zero, excepting the pseudocritical point [22].

For long-range fluctuations of the order parameter, determining the characteristics of molecular light scattering near the pseudospinodal, the inequality $\left.q r_{c}\right|_{s} \ll 1$ for the correlation radius $r_{c}=\left[b_{2} / a_{2}\right]^{1 / 2}$ and the wave vector $\mathbf{q}$ seems to be natural. Therefore, for the integral intensity 
of molecular light scattering $I_{\mathbf{q}}$ near the pseudospinodal we can write:

$$
I_{q} \sim\left\langle\left|\psi_{\mathbf{q}}\right|^{2}\right\rangle=\frac{k_{\mathrm{B}} T}{a_{2}}
$$

where $\psi_{\mathbf{q}}$ is the Fourier-transform of the order parameter. Due to $L_{0} \neq 0$ the concentration dependence of $I_{\mathbf{q}}$ should be nonsymmetric about the axis $x=x_{\mathrm{s}}(T)$. This conclusion agrees with our experimental data.

To determine the pseudospinodal character (concave or convex) it is necessary to study additionally the sign of the derivative $\left.\frac{\partial P_{\mathrm{osm}}}{\partial v}\right|_{T}$ in the vicinity $T=$ $T_{c}+\delta T$ of the pseudocritical point. The pseudospinodal will be a convex curve with the upper critical point if $\left.\frac{\partial P_{\text {asm }}}{\partial v}\right|_{T_{c}+\delta T}<0$ at $\delta T>0$. This inequality is equivalent to

$$
\frac{8}{27} \frac{\tilde{a}^{\prime}\left(T_{c}\right)}{v_{0}}<1, \quad \tilde{a}(T)=\frac{a(T)}{k_{\mathrm{B}}} .
$$

If the opposite inequality

$$
\frac{8}{27} \frac{\tilde{a}^{\prime}\left(T_{c}\right)}{v_{0}}>1
$$

takes place, the pseudospinodal is a concave curve.

The coefficient $a(T)$ and its temperature derivative can be evaluated with the help of the standard expression [23]:

$a(T)=-2 \pi \int_{2 r_{0}}^{\infty}(V(r)+U(r)) r^{2} d r \equiv a_{v}+a_{u}(T)$,

where $V(r)$ is the Hamaker potential [25]

$$
V(r)=-\frac{A}{6}\left\{\frac{2 r_{0}^{2}}{r^{2}-4 r_{0}^{2}}+\frac{2 r_{0}^{2}}{r^{2}}+\ln \left(1-\frac{4 r_{0}^{2}}{r^{2}}\right)\right\}
$$

and $U(r)$ is the contribution caused by the fluctuationmultipole mechanism [26]. The first asymptotic terms of $U(r)$ at $r>2 r_{0}$ have the structure

$$
U(r)=\frac{U_{6}}{r^{6}}+\frac{U_{8}}{r^{8}}+\frac{U_{10}}{r^{10}}+\ldots
$$

where

$$
U_{6}=\frac{9 \alpha_{1}}{\pi}\left\langle\left|\mu_{10}\right|^{2}\right\rangle
$$

and

$$
U_{8}=\frac{15}{2 \pi}\left[3 \alpha_{2}\left\langle\left|\mu_{10}\right|^{2}\right\rangle+5 \alpha_{1}\left\langle\left|\mu_{20}\right|^{2}\right\rangle\right]
$$

In (20) and (21) $\mu_{n 0}$ and $\alpha_{n},\left(\alpha_{n}\right) \equiv \alpha_{n 0}$ are the spherical components of the electric multipole moments and the polarizability tensor of an elementary cluster. Their concrete values can be estimated within more detailed models. Note, unlike the attractive Hamaker potential the contribution $U(r)$ can be both attractive and repulsive [26] depending on peculiarities of the elementary cluster structure. The contributions of $V(r)$ and $U(r)$ are quite comparable (see [26]). Hence the character of the pseudospinodal can noticeably vary for different wateralcohol solutions.

Let us consider the possibility to reproduce qualitatively our experimental data within the proposed approach. We assume that $x_{\mathrm{p}}$ for water-glycerol solutions is slightly smaller than $x_{\mathrm{m}}=0.046$, corresponding to the maximum of the integral intensity and the intersection point of the pseudospinodal and the equilibrium crystallization curve. In this case the isoconcentration line with $x=0.032$ is far from the pseudospinodal and the temperature dependence of the integral intensity $I_{q}$ has no characteristic peculiarities. At $x=0.037$ a system is nearer to the pseudospinodal and the weak maximum of is observed. At further approaching the pseudospinodal $(x=0.040 ; 0.046)$ the maximum of $I_{q}$ becomes higher and clearer. The isoconcentration line $x=0.050$ intersects the pseudospinodal at the temperature $t_{S}^{0}(0.050)$ and increasing the integral intensity is expected. However, this isoconcentration line is removed enough from the threshold concentration $x_{\mathrm{p}}$ and elementary clusters are destroyed. Therefore, the clear peak in the temperature dependence of $I_{q}$ is not observed. The direction of the concentration shift of $T_{\mathrm{m}}$, at which the integral intensity reaches its maximum, shows that in waterglycerol solution the pseudocritical point is upper one and the pseudospinodal is the convex curve. A careful quantitative analysis of all parameters, determining the behaviour of water-glycerol solutions will be performed separately.

The integral intensity smoothly increases when temperature diminishes. This effect can be interpreted as a result of the additional light scattering on the nuclei, which density growths at approaching the equilibrium crystallization curve.

\section{CRYSTALLIZATION OF DILUTE WATER-ALCOHOL SOLUTIONS}

The addition of glycerol molecules to water leads to the decrease of its crystallization temperature. Near $x \approx x_{\mathrm{p}}$, as we saw in Section III, this effect becomes especially noticeable. Let us consider this effect from the thermodynamic positions in more detail.

In pure water the equilibrium crystallization temperature $T_{0}$ at atmospheric pressure $P_{\text {a }}$ satisfies the equation:

$$
\mu^{(\mathrm{w})}\left(P_{\mathrm{a}}, T_{0}\right)=\mu^{(\mathrm{i})}\left(P_{\mathrm{a}}, T_{0}\right)
$$

where $\mu^{(a)}, a=\mathrm{w}, \mathrm{i}$ are the chemical potentials of water in liquid and crystal states (hexagonal ice) correspondingly. At crystallization alcohol molecules are crowded out on the ice surface. Due to this, equation (20) transforms to 


$$
\begin{aligned}
& \mu^{(\mathrm{w})}\left(P_{\mathrm{a}}, T_{0}+\delta T\right)+\delta \mu\left(P_{\mathrm{a}}, T_{0}+\delta T\right) \\
& =\mu^{(\mathrm{i})}\left(P_{\mathrm{a}}, T_{0}+\delta T\right)
\end{aligned}
$$

where $\delta \mu$ is the variation of the chemical potential of water molecules in solution. For $x \ll 1$, from (20) and (21) it follows that the crystallization temperature shifts on the value:

$$
\delta T=-\frac{T_{0}\left[T_{0}\langle x\rangle+\beta\left(P_{\mathrm{a}}, T_{0}\right)\left(\langle x\rangle^{2}+\left\langle\delta x^{2}\right\rangle\right)\right]}{q}+\ldots
$$

Here $q$ is the melting heat, $\beta(P, T)$ is the standard constant of proportionality [22] and $\delta x=x-\langle x\rangle$ is the deviation of concentration from its average value $\langle x\rangle$. The temperature $T_{0}(x)=T_{0}+\delta T_{0}(x)$, where

$$
\delta T_{0}(x)=-\frac{T_{0}^{2}\langle x\rangle}{q}+\ldots,
$$

can be interpreted as the equilibrium crystallization temperature of non-clusterized solution (the Raul's law [22]). The mean square value of $\delta x$ allows the representation:

$$
\left\langle\delta x^{2}\right\rangle=\left\langle\delta x^{2}\right\rangle_{0}\left(\frac{r_{c}}{r_{0}}\right)^{2}
$$

where $\left\langle\delta x^{2}\right\rangle$ and $r_{0}$ are the intensity of fluctuations and the correlation radius at $T=T_{0}$. At approaching the pseudospinodal the ratio $\left(r_{c} / r_{0}\right)$ grows and stimulates the additional lowering of the equilibrium crystallization curve.

In fact, it is necessary to take into account the heterogeneous mechanism of crystallization. In this case the elementary clusters impedes the formation of viable nuclei. Besides, a considerable growth of fluctuations near the pseudospinodal will also destroy the ice nuclei, already formed in a system. Therefore, the effect described by formula (23), should be noticeably weakened. The experimental data on the equilibrium crystallization (see Fig. 4) are in agreement with this conclusion. At the same time in capillaries the role of the heterogeneous mechanism diminishes and the effect (23) is expected to be more clear. The concentration dependence of the metastable crystallization temperature $T_{*}(x)$ and also of the difference $\Delta T$ between it and $T_{c r}(x)$ confirms this fact. From Fig. 4 it follows that $\Delta T$ reaches its maximum at $x \approx x_{\mathrm{p}}$.

At approaching the pseudospinodal the heat capacity of a solution increases also due to the concentration fluctuations. The corresponding contribution $\delta C_{p}(T, x)$ is similar to that for the critical point in the free field approximation [22]:

$$
\Delta C_{p}(T, x)=A r_{c}(T, x)
$$

The peculiarity of the heat capacity close to that was observed in [2].

\section{DISCUSSION}

In the present paper our attention was focused on the clusterization effects in water-alcohol solutions in the low concentration region: $x \leq 0.05$. We assume that in this region the elementary clusters, treated as pseudoparticles, arise. Near $x_{\mathrm{p}}$ the interaction between them leads to the formation of more complex molecular groups. The line separating the states with a different character of the cluster structure is identified with the pseudospinodal of solution. The usage of this notion is correct if the pseudospinodal is not distanced from the percolation threshold $x_{p}$. The behaviour of the concentration fluctuations depends essentially on the relative disposition of the pseudospinodal and the percolation threshold.

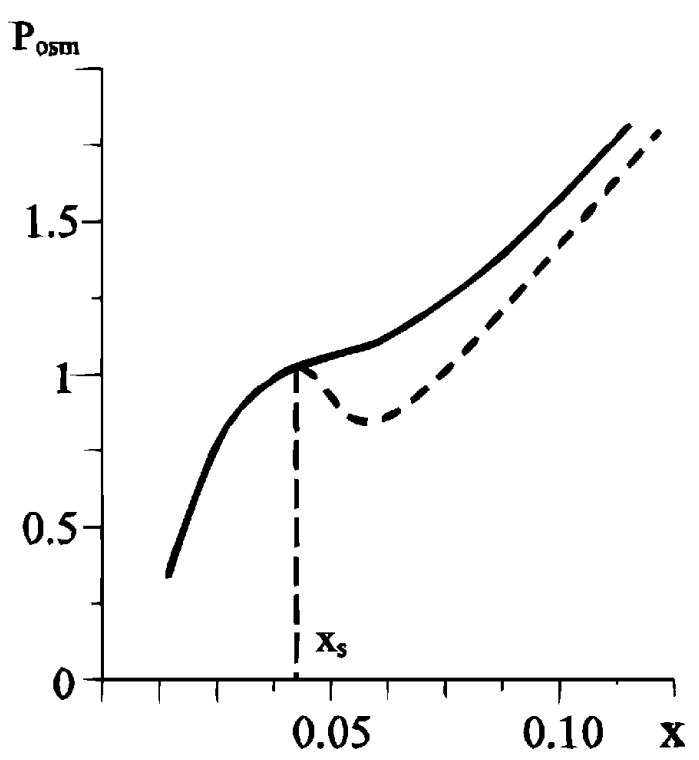

Fig. 6. Schematic concentration dependence of the osmotic pressure in water-alcohol solution: the dotted line corresponds to the case of stable elementary clusters. 


\section{EU. CHECHKO, T .V. LOKOTOSH, N. P. MALOMUZH, V. G. ZAREMBA, V. YA. GOTSUL'SKY}

The elementary cluster in dilute water-glycerol solution, $x \ll x_{\mathrm{p}} \approx 0.046$, includes two molecules of glycerol and $6 \div 10$ molecules of water. Outside it the water structure can be considered as non-perturbed. The similar conclusion is confirmed by the computer simulation of the water structure in water-electrolyte solutions [18]. The elementary cluster is not a static complex. Its life-time is essentially more in comparison with typical time of binary collisions and the residence time for water molecules. The merging of two clusters demands the suitable reorientation of many water molecules and is not energetically profitable. Until the elementary clusters can be considered as a rare gas the osmotic pressure increases with concentration of alcohol molecules. The influence of intercluster attraction and repulsion can be modeled with the help of the van der Waals equation of state. However, at $x \geq x_{\mathrm{p}}$ the elementary clusters destroy. As a result the osmotic pressure at $x \geq x_{\mathrm{p}}$ does not decrease and the derivative $\left.\frac{\partial P_{\mathrm{osm}}}{\partial x}\right|_{T}$ does not tend to zero, although it takes relatively small values. The schematic concentration dependence of the osmotic pressure is presented in Fig. 6.

The considerable increase of the integral intensity of molecular light scattering in water-alcohol solutions near $x \approx 0.05$ is qualified as a manifestation of the pseudospinodal instability. The concentration dependence of the temperature $T_{\max }(x)$ at which the integral intensity reaches its maximum, is the weighty argument in the favour of our picture.

To justify the phenomenological approach presented in this paper the development of the microscopic clusterization theory is very actual. The clusterization reveals itself not only in the equation of state, but also in the peculiarities of dielectric relaxation, nucleation processes in the supercooled solutions, changes of the shear viscosity and so on. The accumulation of detailed experimental data, especially on spectra of molecular light scattering in diluted water-alcohol solutions is also necessary.
[1] M. F. Vuks, Rassieianie svieta v gazakh, zhidkostiakh i rastvorakh (Light scattering in gases, liquids and solutions) (Leningrad University Press, Leningrad, 1977).

[2] M. A. Anisimov, Kriticheskiie iavlenieia v zhidkostiakh i zhidkikh kristallakh (Critical phenomena in liquids and liquid crystals) (Nauka, Moskva, 1987)

[3] R. G. Johnston, N. A. Clark, P. Wiltzius, D. S. Cannel, Phys. Rev. Lett. 54, 49 (1985).

[4] T. Narayanan, A. Kumar, Phys. Rep. 249, 135 (1994).

[5] V. E. Eskin, A. E. Nesterov, Ukr. Phys. J. 9, 540 (1964).

[6] C. W. Beer, D. J. Jolly, Opt. Commun. 11, 150 (1974).

[7] L. V. Lanshina, Russ. J. Phys. Chem. 72, 1110 (1998).

[8] V. E. Chechko, V. G. Zaremba, J. Chem. Phys. 12, 1036 (1993).

[9] T. Katayama, Kagaku Kogaku 26, 361 (1962).

[10] M. F. Vuks, J. Struct. Chem. 14, 673 (1973).

[11] M. A. Anisimov, G. I. Ovodov, J. Struct. Chem. 22, 297 (1981).

[12] L. V. Lanshina, M. N. Rodnikova, I. A. Chaban, Russ. J. Phys. Chem. 66, 204 (1992).

[13] O. Ya. Samoilov, Struktura vodnykh rastvorov eliektrolitov i gidratatsiia ionov (Structure of aqueous electrolyte solutions and the hydration of ions) (AN USSR Press, Moskva, 1957)

[14] T. V. Lokotosh, S. Magazu, G. Maisano, N. P. Malomuzh, Phys. Rev. E 62, 3572 (2000).

[15] R. C. Weast (Ed.), CRS Handbook of Chemistry and
Physics: a Ready-Reference Book of Chemical and Physical Data, 67th Edition (CRS Press, Boca Raton, 1996)

[16] C. A. Angell, Hydrogen-Bonded Liquids, Nato-Asi Series, v. 329 (Kluwer, Dordrecht, 1991).

[17] D. N. Glew, H. D. Mak, N. S. Rath, Hydrogen-Bonded Solvent System, ed. A. K. Covington, P. Jones (London, 1968).

[18] A. Lyubartsev, K. Laasonen, A. Laaksonen, The lecture on EMLG-meeting, Regensburg, 9-13 September, 2000, (in press).

[19] D. Stauffer, Phys. Rep. 54, 1 (1979).

[20] S.-H. Chen, R. Rajagopalan, Micellar Solutions and Microemultions Structure, Dynamics, and Statistical Thermodynamics (Springer-Verlag, New York, Berlin, Heidelberg, London, Paris, Tokyo and Hong Kong, 1990).

[21] F. Franks (ed.), Water: A Comprehensive Treatise (Plenum Press, N. Y., 1972).

[22] L. D. Landau, E. M. Lifshits, Statistical Physics (Pergamon Press, Oxford, 1980).

[23] V. G. Boyko, H.-J. Mogel, A. V. Chalyi, Ukr. Fiz. Zh. 31, 137 (1986).

[24] V. G. Boyko, H.-J. Mogel, A. V. Chalyi, Ukr. Fiz. Zh. 31, 291 (1986).

[25] P. Sherman (ed.) Emulsion Science (Academic Press, London and N. Y., 1968).

[26] A. I. Fisenko, T. V. Lokotosh, N. P. Malomuzh, Physica A, 290, 23 (2001). 


\title{
КЛАСТЕРІЗАЦІЯ ТА АНОМАЛІЇ ФЛУКТУАЦІӤ У ВОДНО-АЛКОГОЛЬНИХ РОЗЧИНАХ МАЛОЇ КОНЦЕНТРАЦЇ̈
}

\author{
В. Є. Чечко, Т. В. Локотош, М. П. Маломуж, В. Г. Заремба, В. Я. Гоцульський \\ Одесъкий начіональний університет \\ вул. Дворянсъка, 2, Одеса, 65100, Украӥна
}

Досліджено аномальну поведінку водних розчинів гліцерину в , піяпазоні малих мольних конпентрапій спирту та температур, близьких до температури кристалізації розчину. Отримано нові експериментальні дані з концентраційної та температурної залежности інтегральної інтенсивности розсіювання світла. ІШоб з'ясувати вплив аномального зростання флюктуапій конщентрапії на зародкоутворення, поставлено експерименти з визначення глибини переохолодження $\Delta T$ як функції концентрації.

Для пояснення природи аномальної поведінки розчинів, а також з'ясування деталей пієї поведінки запропоновано нову конщепцію мікронеоднорідної кластерної структури системи вода-гліцерин. Припущення про склад та розмір кластерів, зроблені на підставі вимоги іх стійкости, підтверджуються ощінками, які випливають з термодинамічного розгляду. Показано, що рівень флюктуаџій концентрапії при конкретних значеннях концентрації $x$ та температури $T$ залежить від положення точки $(x, T)$ щодо двох характерних ліній для розчину пседвочастинок-кластерів - псевдоспінодалі та перколяпійного порога. Тільки коли $(x, T)$ знаходиться близько від обох ліній одночасно, у системі спостерігається аномальне зростання флюктуапій.

У межах кластерної картини знайдено якісне пояснення всіх закономірностей, які спостерігаються на експерименті. 